\title{
EFEKTIFITAS PELATIHAN KOPING RELIGIUS UNTUK MENINGKATKAN KESEJAHTERAAN PSIKOLOGIS PADA PENDERITA DIABETES MELLITUS TIPE 2
}

\author{
Hesty Yuliasari, Hepi Wahyuningsih, RA. Indahria Sulistyarini \\ Fakultas Psikologi dan IImu Sosial Budaya Universitas Islam Indonesia \\ hestyyuliasari@yahoo.com
}

\begin{abstract}
ABSTRAK
Diabetes merupakan salah satu penyakit kronis di Indonesia yangmemaksa individu untuk menyesuaikan dan beradaptasi dengan simptom-simptom penyakit dan perilaku gaya hidupnya. Dalam penanganannya, penyakit diabetes tidak mampu untuk diobati agar menjadi sembuh tetapi dapat dikelola untuk meringankan simptomnya. Pada penderita diabetes, diagnosa dan perjalanan pernyakit akan mempengaruhi kehidupan pasien sehingga menjadi permasalahan yang membutuhkan penanganan tersendiri. Penelitian ini bertujuan untuk mengetahui efektifitas pelatihan koping religius dalam meningkatkan kesejahteraan psikologis pada penderita Diabetes Mellitus Tipe 2. Penelitian ini menggunakan desain non-randomized pretest-posttest control group design. Partisipan dalam penelitian ini adalah 18 penderita Diabetes Mellitus tipe 2. Berjenis kelamin perempuan dan laki-laki beragama Islam yang dikelompokkan dalam dua kelompok. Penelitian ini terdiri dari dua kelompok, satu kelompok $(n=8)$ sebagai kelompok eksperimen yang menerima perlakuan berupa pelatihan koping religius. Satu kelompok lainnya $(n=10)$ sebagai kelompok kontrol. Skala kesejahteraan psikologis yang digunakan, dibuat berdasarkan teori dari Ryff (1989). Kondisi psikologis berkaitan dengan kondisi fisik individu, yang artinya kesehatan tubuh individu akan dipengaruhi oleh pikiran atau pun lingkungan sehingga pikiran yang positif dan lingkungan yang mendukung akan menjadikan kesehatan individu menjadi lebih baik. Uji hipotesis menggunakan analisis non-parametrik berupa Mann Whitney $U$ Test untuk menguji perbedaan nilai berdasarkan kelompok, yaitu eksperimen dan kontrol $(Z=-3,558$ dan $p=0,000$ dimana $p<0,05)$. Dengan demikian, pelatihan koping religius memiliki pengaruh untuk meningkatkan kesejahteraan psikologis penderita diabetes mellitus tipe 2 .
\end{abstract}

Kata kunci: kesejahteraan psikologis, pelatihan koping religius, penderita diabetes mellitus tipe 2.

\section{ABSTRACT}

Diabetes is one of the chronic diseases in Indonesia that force individuals to adjust and adapt to the symptoms of disease and their lifestyle. In the treatment, diabetes is not able to be treated to be cured but can be managed to relieve symptoms. In diabetics, diagnosis and threatment will affect the patient's life so that it becomes a problem that requires its own handling. This study aims to determine the effectiveness of the training of religious coping in improving psychological well-being in patients with Diabetes Mellitus Type 2. The design of this study was non-randomized pretest-posttest control group design. The subjects of this research were 18 patients man or women muslim with diabetes Mellitus Type 2, were classified in two groups: the experimental group and the control group. The study consisted of two groups, one group ( $n=$ 8) as an experimental group who received treatment in the form of training of religious coping. One other group $(n=10)$ as the control group (waiting list). This research used Psychological well-being scale based on the theory of Ryff (1989). Psychological conditions relate to the physical condition of the individual, which means the health of the individual body will be influenced by the mind or the environment so that a positive mind and a supportive environment will make the health of individuals to be better. Hypothesis was tested using testing using non-parametric analyzes Mann Whitney $U$ Test to finding the difference in value based groups, experimental and control. This result based on gain score among posttest and pretest ( $Z=-$ 3.558 and $p=0.000$ where $p<0.05$ ). Thus, religious coping training has the effect to improve the psychological well-being of people with diabetes mellitus type 2.

Keywords: psychological well-being, coping religious training, patients with diabetes mellitus type 2. 


\section{Journal of Psychological Science and Profesion (JPSP)}

Vol.2, No.1, April 2018

E-mail: jurnal.psp@unpad.ac.id

\section{PENDAHULUAN}

Diabetes merupakan salah satu penyakit kronik yang serius di Indonesia saat ini. Penyakit ini dapat menyerang segala lapisan umur dan sosial-ekonomi. Diabetes mellitus dikenal seagai silent killer karena banyak penderitanya yang tidak menyadari namun saat diketahui sudah terjadi komplikasi. Diabetes mellitus tipe 2 adalah penyakit multi-sistem progresif berupa gangguan metabolik yang ditandai kenaikan gula darah akibat penurunan sekresi insulin oleh sel beta pankreas dan ganguan fungsi insulin atau resistensi insulin sehingga mengalami kegagalan menekan sekresi glukosa (Russell-Jones, Vaag, Schmitz,Sethi, Lalic, Antic, Zdravkovic, Ravn \& Simo, 2009).

Diabetes mellitus tipe 2 lebih terkait dengan gaya hidup yang sudah terbentuk pada penderita. Irawan (Trisnawati \& Setyorogo, 2013) menyatakan bahwa demografi, faktor perilaku dan gaya hidup serta keadaan klinis atau mental mempengaruhi peningkatan terjadinya diabetes mellitus tipe 2 .

Diabetes memaksa individu untuk menyesuaikan dan beradaptasi dengan simptomsimptom penyakit dan perilaku gaya hidupnya. Dalam penanganannya, penyakit diabetes tidak mampu untuk diobati agar menjadi sembuh tetapi dapat dikelola untuk meringankan simptomnya. Pada penderita diabetes, diagnosa dan perjalanan pernyakit akan mempengaruhi kehidupan pasien sehingga menjadi permasalahan yang membutuhkan penanganan tersendiri (Alvani, Zaharim \& Kimura, 2015).

Permasalahan - permasalahan yang dikemukakan oleh penderita diabetes mellitus tipe 2 tersebut memengaruhi kondisi kesejahteraan psikologis. Penelitian yang dilakukan Garushi Baneshi \& Moradi (2013) menjelaskan bahwa pada kesejahteraan psikologis berpengaruh terhadap penderita diabetes mellitus. Pada penderita diabetes adanya penurunan kesejahteraan psikologis dikaitkan dengan kontrol glikemik yang cukup, kontrol diri dan komplikasi diabetes yang dialami. Selain itu Garushi, dkk (2013) juga menjelaskan bahwa ketidakmampuan fungsi tubuh, biaya pengobatan, ketergantungan pada orang lain terutama keluarga dapat mempengaruhi kondisi psikologis penderita diabetes.

Pada penyandang diabetes, proses perawatan penyakit ini sangat dirasakan memberatkan pada penderita, terlebih ketika adanya komplikasi yang akan mengarah pada kematian (Jacobson dalam Karlsen \& Bru, 2002). Hal ini membuat penderita harus merubah gaya hidupnya dengan diet dan berolah raga yang juga didukung dengan pengobatan yang rutin dan terus menerus. Penyandang diabetes mellitus tipe 2 sering tidak dapat menerina kondisi dirinya yang memunculkan sikap menyalahkan diri sendiri terhadap pola hidup yang telah dijalani dahulu ataupun ketidak- berhasilan treatment.

Sikap menyalahkan diri sendiri terkait ketidak patuhan dan ketidak berhasilan treatment yang dilakukan untuk mengurangi simptom keparahan penyakit ini. Penelitian yang dilakukan Beverly, et al., (2012) mengungkapkan bahwa pasien penderita diabetes mellitus tipe 2 lebih banyak menyalahkan dirinya sendiri karena tidak melakukan yang seharusnya dilakukan dalam treatment yang dianjurkan sehingga memperburuk kondisi fisik dan psikis.

Selain itu, adanya kontrol terhadap gula darah yang harus dipantau membuat penderita diabetes menjadi tidak mandiri dan tergantung dengan orang lain. Penderita diabetes harus selalu diingatkan dan dilakukan takaran terhadap pola makannya sehingga selalu membutuhkan peran keluarga dan orang lain. Pada individu yang memiliki tingkat kesejahteraan psikologis yang lebih tinggi akan merasakan lebih banyak afek positif dibandingkan afek negatif dalam dirinya (Bradburn dalam Ryff, 1989).

Pada penyandang diabetes mellitus, muncul perasaan negatif berupa penyangkalan terhadap penyakit, menyalahkan diri sendiri dan sikap ketergantungan pada orang lain. Selain itu interaksi dengan lingkungan juga menjadi terbatas sehingga mempengaruhi kesejahteraan psikologis. Campbell (1976) mendefinisikan kesejahteraan psikologis sebagai hasil dari evaluasi yang dilakukan seseorang terhadap hidupnya baik evaluasi secara kognitif maupun evaluasi secara emosi. Evaluasi secara koginitif, kesejahteraan adalah sebuah bentuk kepuasan dalam hidup, sementara sebagai hasil dari evaluasi emosi yaitu berupa perasaan senang.

Dampak yang ditimbulkan berkaitan dengan kesejahteraan yang rendah berupa munculnya kecemasan dan stres yang spesifik pada diabetes seperti khawatir akan komplikasi, terlalu fokus terhadap makanan, muncul perasaan bersalah ataupun malu dan pembatasan terhadap interaksi sosial (Pouwer, 2009). Rendahnya kepercayaan diri terhadap penyakit yang dialami, keharmonisan kehidupan keluarga dan persepsi menyeluruh mengenai kesehatan serta sakit secara negatif berdampak pada penyandang diabetes (Nizami, Abbas, Aslam, Minhas \& Najam, 2005; Singh \& Bradley, 2006).

Pada penyandang diabetes, depresi menjadi penyebab utama ketidakmampuan, ketidakhadiran dalam bekerja dan kehilangan produktivitas (Egede \& Bonadonna, 2003). 


\section{Journal of Psychological Science and Profesion (JPSP)}

Vol.2, No.1, April 2018

E-mail: jurnal.psp@unpad.ac.id

Individu dengan diabetes akan merasa energinya berkurang sehingga mudah lelah dalam melakukan aktivitas sehari-hari, dan menyebabkan aktivitas fisik serta peran dan tanggungjawabnya menjadi berkurang.

Pada penderita diabetes mellitus tipe 2, kesejahteraan psikologis memiliki peran penting untuk mengurangi terjadinya resiko komplikasi. Kondisi psikologis berkaitan dengan kondisi fisik individu, yang artinya kesehatan tubuh individu akan dipengaruhi oleh pikiran atau pun lingkungan sehingga pikiran yang positif dan lingkungan yang mendukung akan menjadikan kesehatan individu menjadi lebih baik (Sundberg, 2007). Hal ini didukung oleh penelitian Clark, Drain, dan Malone (2003) bahwa kondisi psikologis dan emosi seseorang dapat memunculkan permasalahan yang berkaitan dengan kesehatan fisik.

Terapi psikologis dengan pendekatan yang berbasis agama akan membuat penderita menerima kondisi diri dan penyakit yang dialami dengan tetapi berpandangan positif terhadap penyakit yang diberikan oleh Tuhan. Ganje-Fling dan Houg (2008) menjelaskan pentingnya penggunaan intervensi religius yaitu untuk menciptakan hubungan antara individu dengan Tuhan yang memiliki kekuatan di luar kendali manusia. Hal tersebut mampu menambah keyakinan pada diri individu.

Penggunaan keyakinan religius juga sangat membantu dalam proses pemulihan saat sedang menghadapi kesulitan hidup. Hal ini sejalan dengan peran kesejahteraan psikologis dalam penyembuhan dan pencegahan suatu penyakit sehingga dapat meningkatkan harapan hidup pada penderita (Vazquez, Hervas, Rahona, \& Gomez, 2009).

Koping religius banyak dikaitkan dengan berbagai tindakan yang berkaitan terhadap perawatan medis (Cumming \& Pargament, 2010). Koping agama dapat membantu pasien memaknai penyakit dalam konteks spiritual sehingga dapat memaknai secara situasional. Ironson \& Kremer (dalam Cumming \& Pargament, 2010) menjelaskan bahwa pengalaman individu dalam transformasi spiritual dapat mempromosikan tingkat yang lebih tinggi dari makna yang dirasakan dan tujuan hidup, tujuan mencari, dan penerimaan tanggung jawab terhadap pilihan dalam dirinya.

Adanya tujuan hidup dan penerimaan diri berupa tanggung jawab terhadap pilihan merupakan karakteristik individu yang sejahtera secara psikologis (Ryff, 1995). Pajevic, Sinanovic, dan Hasanovic (2005) menambahkan bahwa religiusitas mampu mengurangi kecenderungan beresiko tinggi munculnya perilaku negatif, reaksi impulsif, agresif, kecenderungan perilaku psikopatologis ataupun paranoid. Hal ini menggambarkan bahwa agama dan spiritualitas mampu memberikan kesejahteraan pada individu apabila individu tersebut mendekatkan diri pada Tuhan.

Cumming dan Pargament (2010) mengatakan koping religius dilakukan ketika individu menyadari hidup dan kesehatan adalah hadiah suci bagi individu, atau jika penyakit mengganggu hubungan seseorang dengan Tuhannya. Pargament menjelaskan bahwa koping religus yang lebih positif akan meningkatkan kesehatan mental individu. Tarakeshwar dkk (dalam Cumming \& Pargament , 2010) menjelaskan bahwa individu yang menggunakan koping positif akan berfokus pada Tuhan dan memiliki harapan terhadap bantuan Tuhan dalam menghadapi peristiwa yang menekan. Pada penderita diabetes, rutinitas dalam menjalani kehidupan sebagai penderita diabetes mellitus memberikan tekanan tersendiri.

Terdapat tiga tahapan koping religius positif menurut Pargament dkk (dalam Aflekseir \& Coleman, 2011) berdasarkan aspek-aspek koping religius positif yang juga dikemukakan Pargament, dkk (2001). Tahap pertama adalah adanya keyakinan terhadap kehidupan yang bermakna diberikan oleh Tuhan. Menemukan makna terhadap kebaikan yang Allah berikan dapat berupa perenungan kembali tahap-tahap kehidupan yang telah dilalui. Tahap kedua, menyadari adanya kekuatan Tuhan diluar kendali manusia. Mengekpresikan rasa spiritualitas pada Tuhan dapat terwujud dengan menyadari adanya kekuatan Allah. Pemahaman bahwa segala keputusan yang terjadi pada individu merupakan kendali Allah dan tidak dapat dihindari oleh manusia.

Tahap ketiga, memiliki hubungan yang baik terhadap Tuhan. Membina hubungan baik dengan Tuhan dapat dilakukan dengan terus mengingat adanya Sang Pencipta. Tahap ke empat, membina hubungan baik dengan sesama manusia. Adanya hubungan tolong menolong sesama membuat individu merasa lebih berarti dalam kehidupannya.

Penelitian yang dilakukan Gholamzadeh, Hamid, Basri, Sharif dan Ibrahim (2014) membuktikan bahwa penyelesaian masalah yang berbasis agama dapat mengatasi peristiwa yang menyakitkan dalam kehidupan penderita sehingga memprediksi kesejahteraan yang lebih baik pada individu. Individu yang menilai situasi yang dialami sebagai bagian dari rencana Tuhan ataupun sebagai sarana untuk mendapatkan pemahaman dan kekuatan dari Tuhan melaporkan hal yang lebih positif sehingga 


\section{Journal of Psychological Science and Profesion (JPSP)}

Vol.2, No.1, April 2018

E-mail: jurnal.psp@unpad.ac.id

mempengaruhi kesejahteraan psikologisnya. Hal ini berbeda dengan individu yang merasa kondisi diri sebagai hukuman yang tidak adil dari Tuhan.

Hubungan dengan Tuhan mungkin terpengaruh penilaian individu terhadap situasi dan membantu individu dalam memaham masalah secara positif. Ini juga memberi tujuan dan harapan untuk individu, membantu individu menyesuaikan diri dengan peristiwa sulit. Oleh karena itu, pelatihan koping religius diharapkan dapat meningkatkan kesejahteraan psikologis pada penderita diabetes mellitus tipe 2 .

Berdasarkan penjelasan di atas, dirumuskan hipotesis penelitian. Hipotesis penelitian ini adalah pelatihan koping religius dapat meningkatkan kesejahteraan psikologis pada penderita diabetes mellitus tipe 2. Kelompok yang diberi perlakuan memiliki tingkat kesejahteraan psikologis yang lebih tinggi setelah diberikan pelatihan koping religius dari pada kelompok kontrol yang tidak diberikan pelatihan koping religius.

\section{METODE}

Penelitian ini adalah penelitian kuasieksperimen yaitu penelitian eksperimen yang dilakukan tanpa randominasi, namun masih menggunakan kelompok kontrol (Latipun, 2010). Rancangan eksperimen yang digunakan dalam penelitian ini adalah Non- Randomized PretestPosttest Control Group Design yang desain eksperimennya dilakukan dengan menggunakan pengukuran awal atau pre-test (pretest) sebelum perlakuan dan post-test (posttest) sesudah diberikan perlakuan pada kelompok kontrol dan kelompok perlakuan (Latipun, 2010).

Tabel 1. Rancangan Penelitian

\begin{tabular}{lcccc}
\hline Kelompok & Pre-test & Perlakuan & Post-test & Tindak Lanjut \\
\hline KE & O1 & $\mathrm{X}$ & $\mathrm{O} 2$ & $\mathrm{O} 3$ \\
KK & $\mathrm{O} 1$ & $-\mathrm{X}$ & $\mathrm{O} 2$ & $\mathrm{O} 3$
\end{tabular}

Keterangan :

KE : Kelompok Eksperimen

KK : Kelompok Kontrol

$\mathrm{O} 1$ : Pengukuran sebelum perlakuan (pretest)

$\mathrm{O} 2$ : Pengukuran setelah perlakuan (posttest)

O3 : Pengukuran Tindak Lanjut (follow-up)

$X \quad$ : Pemberian pelatihan koping religius

- X : Tanpa pelatihan koping religius

WL : Waiting List (daftar tunggu)

\section{Subjek Penelitian}

Subjek dalam penelitian ini adalah penderita diabetes mellitus tipe 2 dengan kriteria, sebagai berikut (a) pria atau wanita, (b) berusia 40-60 tahun, (c) beragama Islam dan (d) memiliki skor yang rendah dan sedang dalam kesejahteraan psikologis berdasarkan hasil screening.

\section{Metode Pengumpulan Data}

Untuk mengetahui tingkat kesejahteraan psikologis penyandang diabetes mellitus tipe 2, digunakan skala kesejahteraan psikologis yang diberikan kepada subjek penelitian pada saat pretest, post-test dan tindak lanjut. Skala yang digunakan diadaptasi dari skala yang dibuat oleh Prameswari (2016) yang berjumlah 19 item. Skala kesejahteraan psikologis mencakup 6 aspek yang dikemukakan oleh Ryff (1989), yaitu: penerimaan diri, hubungan positif dengan orang lain, kemandirian, penguasaan terhadap lingkungan adanya tujuan hidup, dan pengembangan potensi diri.

Skala kesejahteraan psikologis ini memiliki butir item yang sahih dengan koefisien validitas item $\geq 0,30$. Koefisien reliabilitas sebesar 0,858 , sedangkan koefisien validitasnya bergerak pada angka antara 0,304- 0,684.

Item-item dalam skala ini merupakan pernyataan dengan empat pilihan jawaban, yaitu "Sangat Sesuai" (SS), "Sesuai" (S), "Tidak sesuai" (S) dan "Sangat Tidak Sesuai" (STS). Rentang skor bergerak dari 1 sampai 4. Bobot penilaian pilihan jawaban untuk item-item favorable yaitu sangat sesuai diberi skor 4 , sesuai diberi skor 3 , tidak sesuai diberi skor 2 , dan sangat tidak sesuai diberi skor 1, sedangkan item-item nonfavourable yaitu sangat sesuai diberi skor 1 , sesuai diberi skor 2, tidak sesuai diberi skor 3 dan sangat tidak sesuai diberi skor 4 .

Semakin tinggi nilai yang diperoleh subjek pada skala ini, maka semakin tinggi kesejahteraan psikologis yang dimiliki. Semakin rendah nilai yang diperoleh subjek, maka semakin rendah kesejahteraan psikologis yang dimiliki subjek.

\section{Prosedur Penelitian}

Ada beberapa tahapan pelaksanaan dalam penelitian ini. Pertama, persiapan. Pada tahap ini peneliti melakukan analisis kebuTuhan dengan menggunakan wawacara maupun studi pustaka yang dilanjutkan dengan pelengkapan perizinan pada pihak terkait. Setelah itu, penyusunan modul pelatihan dan melakukan uji coba modul. Modul pelatihan koping religius ini merupakan modifikasi dari modul pelatihan yang dikembangkan oleh Amita (2016).

Pengambilan sampel penelitian dilakukan berdasarkan screening hasil pre-test yang dilakukan. Pengelompokkan subjek ini tidak dipilih 


\section{Journal of Psychological Science and Profesion (JPSP)}

Vol.2, No.1, April 2018

E-mail: jurnal.psp@unpad.ac.id

secara random, melainkan berdasarkan kemudahan sehingga mendapatkan jumlah subyek yang memadai untuk mewakili kategori karakteristik tertentu di dalam sampel. Pembagian kelompok dilakukan dengan mempertimbangkan kesediaan setiap subjek yang telah di screening untuk bersedia menghadiri pelatihan yang akan diadakan sesuai waktu dan tempat. Subjek yang bersedia mengikuti pelatihan ditempatkan dalam kelompok eksperimen, sedangkan subjek yang tidak dapat menghadiri pelatihan ditempatkan di kelompok kontrol.

Persiapan lain sebelum dilakukan intervensi yaitu pemilihan trainer dan co-fasilitator. Trainer merupakan psikolog ataupun terapis yang memiliki surat izin praktek, beragama Islam, memiliki pengetahuan mengenai terapi koping religius ataupun terapi Islami, memiliki pengalaman sebagai terapis atau ko-terapis terapi koping religius ataupun terapi Islami, memahami materi mengenai modul pelatihan, mampu menyampaikan materi kepada peserta sesuai dengan prosedur yang tertulis dalam modul pelatihan. Co-fasilitator merupakan mahasiswa Magister Psikologi Profesi psikolog bidang klinis dan telah menjalani praktik kerja profesi psikolog, beragama Islam, dan memahami materi mengenai terapi koping religius atau terapi Islami.

Tahap kedua, pelaksanaan intervensi. Intervensi yang diberikan dalam penelitian ini adalah pelatihan koping religius. Pelatihan diberikan pada kelompok eksperimen dengan jumlah peserta sebanyak 8 orang. Pelatihan koping religius ini dilakukan selama dua kali pertemuan dengan durasi kurang lebih 120 sampai 150 menit pada setiap pertemuannya. Materi yang diberikan selama pelatihan berupa materi harapan dan keinginan, menemukan makna kebaikan Allah SWT, menonton film, menciptakan hubungan baik dengan mengingat Allah, dan tolong menolong sesama.

\section{Metode Analisis Data}

Metode analisis data yang digunakan berupa analisis data kuantitaif metode statistik dengan teknik analisis Mann Whitney $U$ test pada gained score dengan bantuan program SPSS 20.00 for windows untuk menguji perbedaan nilai berdasarkan kelompok, yaitu eksperimen dan kontrol. Perbedaan tingkat kesejahteraan psikologis akibat adanya hasil perlakuan diamati secara berulang-ulang, yaitu sebelum perlakuan (pre-test), setelah perlakuan (post-test), dan tindak lanjut (follow up).

Selain itu dilakukan pula analisis secara kualitatif untuk setiap individual yang bertujuan untuk menjelaskan apa saja yang dirasakan pada masing-masing individu dalam proses pelatihan.
Proses analisis data secara kualitatif dilakukan dengan analisis deskriptif dengan mengolah data yang diperoleh dari observasi dan tulisan subjek serta wawancara.

\section{HASIL DAN PEMBAHASAN}

\section{Deskripsi data penelitian}

Data dalam penelitian ini mendeskripsikan 18 subjek penelitian yang terdiri dari 8 sujek kelompok eksperimen dan 10 subjek kelompok kontrol. Kelompok eksperimen terdiri dari 2 orang laki-laki dan 6 orang perempuan, sedangkan kelompok kontrol terdiri dari 4 orang laki-laki dan 6 orang perempuan.

Tabel 2. Deskripsi Data Subjek Penelitian Kelompok Eksperimen

\begin{tabular}{|c|c|c|c|c|c|c|c|}
\hline \multirow[b]{2}{*}{ Subjek } & \multirow[b]{2}{*}{ JK } & \multicolumn{6}{|c|}{ Pengukuran } \\
\hline & & $\begin{array}{l}\text { Pre- } \\
\text { test }\end{array}$ & $\begin{array}{c}\text { Post- } \\
\text { test }\end{array}$ & $\begin{array}{l}\text { Tindak } \\
\text { lanjut }\end{array}$ & $\begin{array}{c}\text { Gained } \\
\text { score } \\
\text { (pasca- } \\
\text { pra) }\end{array}$ & $\begin{array}{c}\text { Gained } \\
\text { score } \\
\text { (tindak } \\
\text { lanjut- } \\
\text { pasca) }\end{array}$ & $\begin{array}{c}\text { Gained } \\
\text { score } \\
\text { (tindak } \\
\text { lanjut- } \\
\text { pra) }\end{array}$ \\
\hline MY & $\mathrm{L}$ & 44 & 59 & 61 & 15 & 2 & 17 \\
\hline AR & L & 53 & 63 & 64 & 10 & 1 & 11 \\
\hline EP & $P$ & 42 & 58 & 61 & 14 & 3 & 17 \\
\hline IN & $P$ & 44 & 63 & 67 & 19 & 4 & 23 \\
\hline YY & $P$ & 43 & 63 & 65 & 20 & 2 & 22 \\
\hline RE & $P$ & 44 & 64 & 66 & 20 & 2 & 22 \\
\hline NN & $P$ & 46 & 62 & 63 & 16 & 1 & 17 \\
\hline TT & $\mathrm{P}$ & 46 & 58 & 56 & 12 & -2 & 10 \\
\hline
\end{tabular}

Berdasarkan tabel di atas, keseluruhan subjek mengalami perubahan kategori kesejahteraan psikologis setelah pelaksanaan pelatihan yaitu dari rendah menjadi tinggi. Pada pelaksanaan tindak lanjut, tujuh subjek mengalami mengalami peningkatan skor namun tidak begitu signifikan dan satu subjek mengalami penurunan skor pada pelaksanaan tindak lanjut, namun masih berada dalam kategori tinggi.

Tabel 3. Deskripsi Data Subjek Penelitian Kelompok Kontrol

\begin{tabular}{|c|c|c|c|c|c|c|c|}
\hline \multirow[b]{2}{*}{ 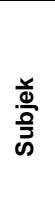 } & \multirow[b]{2}{*}{ 产 } & \multicolumn{6}{|c|}{ Pengukuran } \\
\hline & & $\frac{\overleftarrow{d}}{\frac{d}{d}}$ & $\begin{array}{l}\bar{\Phi} \\
\stackrel{2}{\$} \\
\vdots \\
\vdots \\
0 \\
0\end{array}$ & 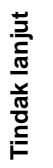 & 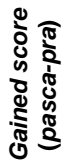 & 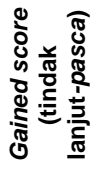 & 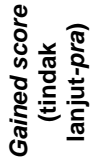 \\
\hline PM & $P$ & 48 & 44 & 43 & -4 & -1 & -5 \\
\hline WN & $\mathrm{P}$ & 47 & 45 & 46 & -2 & 1 & -1 \\
\hline PJ & $P$ & 44 & 44 & 43 & 0 & -1 & -1 \\
\hline $\mathrm{KR}$ & $P$ & 44 & 45 & 45 & 1 & 0 & 1 \\
\hline SI & $\mathrm{P}$ & 48 & 43 & 43 & -5 & 0 & -5 \\
\hline $\mathrm{KW}$ & $P$ & 46 & 43 & 42 & -3 & -1 & -4 \\
\hline IS & L & 48 & 43 & 43 & -5 & 0 & -5 \\
\hline BM & L & 47 & 47 & 46 & 0 & -1 & -1 \\
\hline WM & L & 46 & 38 & 36 & -8 & -2 & -10 \\
\hline JI & L & 45 & 38 & 38 & -7 & 0 & -7 \\
\hline
\end{tabular}




\section{Journal of Psychological Science and Profesion (JPSP)}

Vol.2, No.1, April 2018

E-mail: jurnal.psp@unpad.ac.id

Berdasarkan tabel tersebut terlihat selisih skor post-test dan pre-test, maka dapat dilihat bahwa tujuh orang subjek mengalami penurunan skor kesejahteraan psikologis dengan rentang skor 1 hingga 8. Pada pelaksanaan tindak lanjut eat orang subjek mengalami penurunan skor 1 hingga 10.

Tabel 4. Deskripsi statistik skor kesejahteraan psikologis pada dua kelompok

\begin{tabular}{cccccccccc}
\hline & \multicolumn{4}{c}{ Kelompok Eksperimen } & \multicolumn{3}{c}{ Kelompok Kontrol } \\
\cline { 2 - 7 } Klasifikasi & Min & Maks & Mean & SD & Min & Maks & Mean & SD \\
\hline Pre-test & 48 & 53 & 45,5 & 3,21 & 44 & 48 & 46,3 & 1,57 \\
Post-test & 58 & 64 & 61,25 & 2,49 & 38 & 47 & 43 & 2,91 \\
$\begin{array}{c}\text { Tindak } \\
\text { lanjut }\end{array}$ & 56 & 67 & 62,88 & 3,52 & 36 & 46 & 42,5 & 3,24 \\
\hline
\end{tabular}

Tabel di atas menunjukkan bahwa pada saat pelaksanaan pre-test, post-test, dan tindak lanjut, terdapat perbedaan nilai mean antara kelompok eksperimen dan kelompok kontrol. Kelompok eksperimen mengalami peningkatan skor pada saat post-test dan tindak lanjut. Sedangkan kelompok kontrol, apabila dilihat dari nilai mean justru mengalami penurunan skor, meskipun tidak cukup signifikan.

\section{Hasil Uji Hipotesis}

Uji hipotesis non-parametrik yang akan dilakukan adalah Mann Whitney $U$ Test. Selain karena uji asumsi tidak terpenuhi, uji nonparametrik ini juga digunakan dengan pertimbangan jumlah subjek penelitian yang terbatas. Uji hipotesis bertujuan untuk mengetahui apakah ada perbedaan antara kelompok eksperimen dan kelompok kontrol.

Tabel 5. Hasil Uji Hipotesis

\begin{tabular}{lccl}
\hline \multicolumn{1}{c}{ Data } & $\mathbf{Z}$ & $\mathbf{P}$ & Keterangan \\
\hline Pasca-Pre-test & $-3,558$ & 0,000 & Signifikan \\
Tindak lanjut-Pre-test & $-3,578$ & 0,000 & Signifikan \\
Tindak lanjut-Post-test & $-2,571$ & 0,010 & Signifikan \\
\hline
\end{tabular}

Hasil analisis Mann Whitney yang telah dilakukan menggunakan data gain score. Data gain score post-test dengan pre-test menunjukkan ada perbedaan skor kesejahteraan psikologis yang signifikan dilihat dari nilai $Z=-3,558$ dan $p=$ $0,000 \quad(p<0,05)$. Data gain score tindak lanjut dengan pre-test menunjukkan ada perbedaan skor kesejahteraan psikologis yang signifikan dilihat dari nilai $Z=-3,578$ dan $p=0,000(p<0,05)$. Hal ini juga terjadi pada data gain score tindak lanjut dengan post-test yang menunjukkan bahwa nilai $Z=-2,571$ dan $p=0,010(p<0,05)$ yang berarti ada perbedaan skor kesejahteraan psikologis yang signifikan pada data gain score tindak lanjut dengan post-test.

\section{Pembahasan}

Penelitian ini bertujuan untuk menguji hipotesis pelatihan koping religius dalam meningkatkan kesejahteraan psikologis pada penderita diabetes mellitus tipe 2. Pengukuran kesejahteraan psikologis dilakukan sebelum dan sesudah pelatihan koping religius diberikam, serta pada tindak lanjut kelompok eksperien dan kelompok kontrol. Berdasarkan analisis kuantitatif dengan menggunakan uji non-parametrik Mann Whitney $U$ Test, menunjukkan ada perbedaan yang signifikan pada saat pelaksanaan post-test dan tindak lanjut antara kelompok eksperimen dengan kelompok kontrol. Berdasarkan penjelasan di atas, maka dapat disimpulkan bahwa pelatihan koping religius memiliki pengaruh untuk meningkatkan kesejahteraan psikologis penderita diabetes mellitus tipe 2 .

Pelatihan koping religius ini terdiri dari empat tahapan yang dirumuskan menjadi empat materi yaitu menemukan makna kebaikan Allah, menyadari adanya kekuatan Allah diluar kendali manusia, menciptakan hubungan baik dengan mengingat Allah dan hubungan baik dengan sesama manusia. Keterampilan pertama yang diajarkan adalah menemukan makna kebaikan Allah. Subjek diharapkan dapat memahami dengan memandang penyakit diabetes mellitus dari sisi yang positif . Hal ini sejalan dengan penyataan Koenig (Octarina \& Afiatin 2011) bahwa pemaknaan yang terbentuk dari pemikiran dan interpretasi yang positif akan menimbulkan suatu harapan dan perasan yang positif.

Pandangan positif yang dimiliki oleh subjek diabetes meliitus meyakini bahwa Allah memberikan cobaan bukan sebagai hukuman melainkan untuk dapat menjadi pribadi yang lebih baik. Penelitian ini didukung oleh penelitian Ano dan Vasconcellos (2005) yang menjelaskan bahwa koping religius positif akan memberikan pandangan yang positif dari kejadian yang membuat individu stres dengan memandang cobaan dari Tuhan sebagai alasan untuk dapat berbagi beban dengan Tuhan.

Setelah subjek mampu memaknai kebaikan Allah dalam kehidupannya, subjek diberikan materi menyadari adanya kekuatan Allah di luar kendali manusia. Subjek menyadari bahwa yang terjadi dalam hidup manusia tidak dapat dikendalikan oleh manusia melainkan sudah di tetapkan oleh Allah dan manusia diharapkan menerima setiap takdir dalam hidupnya. Hal ini 


\section{Journal of Psychological Science and Profesion (JPSP)}

Vol.2, No.1, April 2018

E-mail: jurnal.psp@unpad.ac.id

dikarenakan Allah menjadi penentu atas setiap kejadian yang dialami oleh manusia.

Hasil ini didukung oleh penelitian Roemarin, Pargament dan Robb (2010) yang menjelaskan bahwa keyakinan terhadap agama dan Tuhan akan mempengaruhi perilaku adaptif yang menolong individu menghadapi setiap peristiwa yang memberikan dampak stres secara psikologis. Setiap individu yang sakit selalu berharap agar dirinya dapat sembuh. Adanya sikap untuk berharap akan mampu menerima kondisi diri sehingga memiliki energi yang lebih untuk memotivasi diri dengan berperan aktif menghadapi permasalahan dan menjadi individu yang terus berkembang (Bluvol dan Marilyn, 2004).

Materi menciptakan hubungan baik dengan mengingat Allah dilakukan melalui praktek zikir. Saat individu muslim melakukan zikir, muncul perasaan bahwa dirinya dekat dengan Allah, berada dalam penjagaan dan lindungan-Nya, yang kemudian akan membangkitkan percaya diri, kekuatan, perasaan aman, tenteram, dan bahagia (Najati, 2005). Praktek zikir membuat subjek diabetes pada pelatihan ini merasakan kedekatannya dengan Allah, zikir juga menjadi waktu yang tepat untuk berserah diri dan mengadu pada Allah, selain itu subjek juga merasakan zikir memberikan ketenangan dari pikiran dan perasan negatif mengenai persepsi dalam menjalani hidup dengan penyakit diabetes.

Pelafalan zikir dengan astagfirullah haladzim mampu memberikan ketenangan dalam diri subjek. Yusrialdi (Anggraini \& Subandi, 2014) menjelaskan bahwa proses zikir yang mengucapkan kalimat yang mengandung huruf jahr, seperti kalimat tauhid dan istighfar dapat meningkatkan pembuangan $\mathrm{CO} 2$ dalam paruparu. Paru-paru yang banyak memiliki banyak $\mathrm{O}_{2}$ akan mengalirkan banyak oksigen pada tubuh hingga ke otak sehingga tubuh menjadi lebih segar dan mampu berfikir lebih jernih. Penelitian Jaspere, Ward dan Jose (2012) mendukung penelitian peneliti bahwa kegiatan keagamaan seperti berdoa, zikir dan membaca Al-Qur'an memberikan manfaat sebagai pemaknaan terhadap koping untuk mencapai kesembuhan dan harapan hidup.

Tahapan selanjutnya adalah tolong menolong sesama. Materi ini diberikan pada peserta agar subjek meningkatkan interaksi sosial di lingkungannya. Berdasarkan lembar kerja yang dikerjakan subjek, subjek telah menerapkan interaksi sosial terhadap lingkungannya dengan sikap tolong menolong. Subjek merasa tolong menolong memberikan rasa adanya dukungan terhadap permasalahan yang dihadapi sehingga subjek merasa dirinya bermanfaat.
Hal ini sejalan dengan penelitian Miller dan Dimatteo (2013) bahwa pada pasien usia dewasa, dukungan sosial dari keluarga dan teman membantu pasien menerima secara aktif terhadap perubahan kondisi fisik, sosial dan ekonomi yang dimiliki. Keberfungsian keluarga menjadi hal yang penting dan mempengaruhi kontrol terhadap gula darah penderita diabetes. Dukungan dari teman sebaya dan lingkungan akan mempengaruhi pandangan penderita diabetes terhadap penyakit yang dideritanya (Dale, Williams, \& Bowyer, 2012). Subjek dalam penelitian ini memahami bahwa sikap subjek dalam lingkungan akan mempengaruhi interaksi dan dukungan sosial lingkungan terhadap diri subjek.

Peserta AR mengalami peningkatan skor kesejahteraan psikologis terendah jika dibandingkan dengan peserta lainnya. Adanya pemahaman terhadap religiusitas dalam diri menyebabkan AR kesulitan dalam menyerap materi yang menerapkan nilai-nilai religiusitas selama pelatihan, namun AR tetap mencoba untuk menerapkan salah satu sesi yang didapatkan dalam pelatihan.

AR memaknai bahwa nilai-nilai religiusitas mampu membuat AR memandang masalah dengan cara yang berbeda. Penelitian yang dilakukan Krok (2014) menjelaskan bahwa agama dan nilai-nilai religiusitas memungkinkan individu untuk memahami kehidupan di dunia dalam menemukan makna dan tujuan dalam hidup. Individu mampu untuk menilai agama sebagai faktor utama dalam mencapai tujuan hidup dengan menjadikan agama dan nilai-nilai religiusitas sebagai motivasi utama.

Kenaikan skor yang cukup tinggi dialami oleh subjek YY dan RE. Pada subjek YY, kenaikan skor dikarenakan adanya kemampuan subjek untuk dapat mengontrol rasa takut dalam menghadapi penyakit diabetes mellitus yang di derita. Hal ini sesuai dengan penelitian McConnell, Pargament, Ellison, \& Flannelly (2006) bahwa strategi koping religius berkaitan dengan kesejahteraan umum dan kesehatan emosional, dan juga kondisi psikopatologi, termasuk kecemasan umum, kecemasan fobia, depresi, paranoid, obsesif kompulsif, dan somatisasi.

Pada pelatihan koping religius, subjek menyadari pemaknaan yang lebih positif terhadap penyakit yang di derita dapat memberikan ketenangan sehingga subjek mampu mengontrol rasa takut menghadapi penyakit yang dideritanya. $\mathrm{Hal}$ ini sesuai dengan salah satu dari lima fungsi dasar metode koping religius berupa pemahaman makna untuk mendapatkan perubahan dalam 


\section{Journal of Psychological Science and Profesion (JPSP)}

Vol.2, No.1, April 2018

E-mail: jurnal.psp@unpad.ac.id

menjalani hidup (Pargament, Koenig \& Perez, 2000)

Terbuktinya hipotesis dalam penelitian ini senada pula dengan penelitian yang dilakukan oleh Ghomladezh (2014) yang menunjukkan bahwa koping religius berpengaruh terhadap kesejahteraan psikologis pada caregiver stroke di Iran. Hasil dari penelitian ini adalah ada perbedaan peningkatan kesejahteraan psikologis pada kelompok eksperimen dengan kelompok kontrol. Peningkatan kesejahteraan psikologis kelompok eksperimen lebih besar dari pada kelompok kontrol. Artinya dengan mengikuti pelatihan koping releigius, maka subjek dapat melakukan penanganan terhadap permasalahan psikologis selama menderita diabetes yang akan berdampak pada meningkatnya kesejahteraan psikologis yang dimiliki.

Pada suatu pelatihan, terdapat beberapa faktor yang mempengaruhi keberhasilan suatu pelatihan yaitu materi yang dibutuhkan, metode yang digunakan, kemampuan instruktur pelatihan, peserta pelatihan, serta evaluasi pelatihan. Metode yang digunakan dalam pelatihan ini berupa ceramah, diskusi, teknik audiovisual, refleksi, permainan, dan praktek sehingga memberikan variasi yang membuat pelatihan tidak membosankan. Adanya sikap kooperatif dari para peserta yang memiliki komitmen untuk mengikuti pelatihan dari sesi awal hingga akhir. Selain itu, adanya pendekatan kelompok yang memberikan umpan balik dan rasa kebersamaan dari para peserta menumbuhkan rasa bahwa peserta mendapatkan dukungan dari peserta lainnya yang juga mengidap penyakit diabetes mellitus.

Kelemahan dari pelatihan koping religius ini adalah durasi dari dua pertemuan tersebut dirasakan sangat kurang dan terasa singkat bagi para peserta untuk memberikan materi serta melatih kemampuan peserta pelatihan yang memiliki keberagaman usia. Peneliti juga mempertimbangkan kelelahan fisik dan psikis yang dirasakan oleh peserta, jika intervensi ini diberikan selama lebih dari tiga jam akan berpengaruh pada kefektifan dari sebuah pelatihan.

Selain itu, banyaknya lembar kerja yang harus dikerjakan oleh peserta dibandingkan sesi praktek sehingga materi yang memiliki lembar kerja dirasa kurang optimal memberikan pengaruh pada peserta. Pengelompokan subjek yang dilakukan peneliti berpengaruh terhadap hasil perubahan skor kelompok kontrol meskipun tidak diberikan perlakuan. Peneliti mengelompokkan subjek pada kelompok kontrol dan kelompok eksperimen berdasarkan kebersediaan subjek untuk dapat hadir pada hari pelatihan.

\section{SIMPULAN}

\section{Simpulan}

Penelitian ini membuktikan terdapat perbedaan tingkat kesejahteraan psikologis yang signifikan antara penderita diabetes mellitus tipe 2 yang mendapat pelatihan koping religius dan yang tidak mendapatkan pelatihan koping religius. Hal ini dapat diketahui dari perubahan skor yang didapatkan sebelum dan sesudah pelatihan koping religius dilaksanakan. Kelompok eksperimen mengalami peningkatan skor kesejahteraan psikologis secara signifikan sedangkan kelompok kontrol yang tidak mendapatkan pelatihan koping religius mengalami penurunan skor kesejahteraan psikologis.

\section{Saran}

Bagi peneliti selanjutnya yang menggunakan pelatihan koping religius perlu untuk memperhatikan materi pelatihan. Apabila subjek penelitian memiliki keterbatasan waktu dan pertimbangan keterbatasan kemampuan, maka pelatihan dapat dilakukan dalam bentuk praktik dan mengurangi lembar kerja pertemuan dengan waktu yang singkat. Pemilihan materi dalam modul pelatihan diharapkan dapat sesuai dengan usia dari subjek pelatihan, sehingga subjek mampu memahami materi yang didapatkan dan menerapkannya sesuai dengan kondisi subjek. Peneliti dapat mengukur tingkat religiusitas subjek terlebih dahulu dikarenakan pelatihan koping religius mencakup nilai-nilai religiusitas dalam penerapan materi sehingga subjek merasakan manfaat pelatihan terkait dengan nilai-nilai religiusitas yang dimiliki subjek.

Secara praktis, pelatihan koping religius ini dapat dijadikan pertimbangan dalam mengatasi permasalahan psikologis penderita diabetes mellitus tipe 2 yang terus meningkat setiap tahun. Puskesmas dan Pelayanan kesehatan lainnya dapat secara rutin mengagendakan pelatihan serupa dengan pelatihan koping religius yang telah diberikan pada penderita diabetes mellitus tipe 2. Hal ini dimaksudkan agar penderita dapat menjalankan fungsi psikologisnya secara optimal, meskipun banyaknya keterbatasan fisik akibat penyakit diabetes mellitus tipe 2 .

\section{DAFTAR PUSTAKA}

Aflakseir, A., \& Coleman, P. G. (2011). Initial development of the Iranian religious coping scale. Journal of Muslim Mental Health, 6 (1) , 45-61. 


\section{Journal of Psychological Science and Profesion (JPSP)}

Vol.2, No.1, April 2018

E-mail: jurnal.psp@unpad.ac.id

Alvani, S. R., Zaharim, N. M., \& Kimura, L. W. (2015). Effect of group cognitive behavioral therapy (CBT) on psychological well-being and glycemic control in adults with type 2 diabetes. International Journal of Diabetes in Developing Countries, 35(2), 284-289. doi:10.1007/s13410-015-0415-z

Amita, N. (2016). Pelatihan koping religius dalam menurunkan kecemasan pada penderita kista ovarium. Tesis, tidak diterbitkan. Fakultas Psikologi dan IImu sosial budaya UII, Yogyakarta.

Anggraieni, W. N., \& Subandi, S. (2014). Pengaruh Terapi Relaksasi Zikir untuk Menurunkan Stres pada Penderita Hipertensi Esensial. JIP: Jurnal Intervensi Psikologi, 6(1), 81-102.

Ano, G. G., \& Vasconcelles, E. B. (2005). Religious coping and psychological adjustment to stress: A meta-analysis. Journal of clinical psychology, 61(4), 461480.

Beverly, E. A., Ritholz, M. D., Brooks, K. M., Hultgren, B. A., Lee, Y., Abrahamson, M. J., \& Weinger, K. (2012). A Qualitative Study of Perceived Responsibility and Self-Blame in Type 2 Diabetes: Reflections of Physicians and Patients. Journal of General Internal Medicine, 27(9), 1180-1187. doi:10.1007/s11606-012-2070-0

Bluvol, A, \& Marilyn, F. G. (2004). Hope, health work and quality of life in families of stroke survivors. Journal of Advanced Nursing, 48, 322-332.

Campbell, A. (1976). Subjective measures of wellbeing. American Psychologist, 31, 117124.

Clark, P. A., Drain, M., \& Malone, M. P. (2003). Addressing patients' emotional and spiritual needs. The Joint Commission Journal on Quality and Safety, 29(12), 659-670.

Cummings, J. P. \& Pargament, K. I. (2010). Medicine for the spirit: Religious coping in individuals with medical conditions. Religions, 1, 28-53.

Dale, J. R, Williams, S. M, Bowyer, V. (2012). What is the effect of peer support on diabetes outcomes in adults? A systematic review. Diabet Med, 29, 1361-1377.

Egede, L.E. \& Bonadonna, R.J. (2003). Diabetes self-management in African Americans: An exploration of the role of fatalism. The Diabetes Educator, 29(1), 105-115.

Garushi, B., Baneshi, M. R, \& Moradi, S. (2013). Psychosocial contributing factors that affect mental well being in diabetic patients.
Russian Open Medical Journal, 2, 1 - 5

Gholamzadeh, S., Hamid, T. A., Basri, H., Sharif, F., \& Ibrahim, R. (2014). Religious coping and psychological well-being among Iranian stroke caregivers. Iranian Journal of Nursing and Midwifery Research, 19(5), 478-484.

Houg, B. L. (2008). The role of spirituality in the ongoing recovery process of female sexual abuse survivors. University of Minnesota

Jasperse, M., Ward, C., \& Jose, P. E. (2012). Identity, perceived religious discrimination, and Psychological well-being in Muslim immigrant women. Applied Psychology, 61(2), 250-271.

Karlsen, B. \& Bru, E. (2002). Coping styles among adult with type 1 and type 2 diabetes. Psychology, Health \& Medicine, 7 (3), 245259.

Krok, D. (2014). The mediating role of coping in the relationships between religiousness and mental health. Psychiatry and Psychotherapy, 2, 5-13.

Latipun. (2010). Psikologi eksperimen. Malang: Universitas Muhammadiyah Malang

McConnell, K.M, Pargament, K.I, Ellison,C.G, \& Flannelly, K.J. (2006). Examining the links between spiritual struggles and symptoms of psychopathology in a national sample. Journal of Clinical Psychology, 62:14691484.doi:10.1002/jclp.20325.

Miller, T.A. \& Di Matteo, M. R. (2013). Importance of family and social support and impact on adeherence to diabetic therapy. Diabetes, Metabolic Syndrome and Obesity: Targets and Therapy, 6, 421-426. http://dx.doi.org/10.2147/DMSO.S36368

Najati, M.U. (2005). Al-qur'an dan Psikologi (Terjemahan). Jakarta: Aras Pusaka

Nizami, A., Abbas, S., Aslam, F., Minhas F. A., \& Najam, N. (2005). Relationship between anxiety, depression, psychological wellbeing and quality of life in patients having hemodialysis. Journal of Pakistan Psychiatric Society, 2(2), 80-84.

Octarina, M. \& Affiatin, T. (2013). Efektivitas pelatihan koping religius untuk meningkatkan resiliensi pada perempuan penyintas erupsi merapi. Jurnal intervensi Psikologi, 5 (1), 95-110.

Pargament, K.I. Koenig, H. G., \& Perez, L. M. (2000). The Many Methods of Religious Coping: Development and Initial Validation of the RCOPE. Journal of Clinical Psychology, 56(4), 519-543.

Pargament, K.I., Tarakwshwar, N., Ellison, C.G., \& Wulff, K.M. (2001). Religious coping among the religious: The relationships 
Vol.2, No.1, April 2018

E-mail: jurnal.psp@unpad.ac.id

between religious coping and wellbeing in a national sample of Presbyterian clergy, elders, and members. Journal for the Scientific Study of Religion, 40(3), 497-513.

Pajevic, I., Sinanovic, O. \& Hasanovic, M. (2005). Religiosity and mental health. Psychiatria Danubina, 17(1-2), 84-89

Pouwer F. (2009). Should we screen for emotional distress in type 2 diabetes mellitus? Nature Reviews. Endocrinology, 5(12), 665-671.

Prameswari, R. (2016). Pengaruh terapi zikir dalam meningkatkan kesejahteraan psikologis pada penerita hipertensi. Tesis, tidak diterbitkan. Fakultas Psikologi dan IImu sosial budaya UII, Yogyakarta.

Russell-Jones, D., Vaag, A., Schmitz, O.,Sethi, B. K.,Lalic, N., Antic, S.,Zdravkovic, M., Ravn, G. M., \& Simo, R. (2009). Liraglutide vs insulin glargine and placebo in combination with metformin and sulfonylurea therapy in type 2 diabetes mellitus (LEAD- 5 met+SU): a randomised controlled trial. Diabetologia, 52(10), 2046-2055.

Rosmarin, D.H., K.I. Pargament \& Robb, H.B. (2010). Spiritual and religious issues in behavior change. Cognitive and Behavioral Practice, 17: 343-347.

Ryff, C.D. (1989). Happiness is Everything, or is it? Exploration on the meaning of Psychological Well-being. Journal Personality and Social Psychology, 57 (6), 1069-1081.

Ryff, C. D. (1995). Psychological well-being in adult life. Current Directions in Psychological Science, 4, 99-104.

Singh, H., \& Bradley C. (2006). Quality of life in diabetes. International Journal of Diabetes in developing Countries, 26(1), 7-10.

Sundberg, ND. (2007). Psikologi Klinis Edisi ke Empat. Yogyakarta: Pustaka pelajar.

Trisnawati, S. K. \& Setyorogo, S. (2013). Faktor risiko kejadian diabetes mellitus tipe II di Puskesmas Kecamatan Cengkareng Jakarta Barat tahun 2012. Jurnal ilmiah kesehatan, 5 (1), 6- 11.

Vázquez, C., Hervás, G., Rahona, J. J., \& Gómez, D. (2009). Psychological well-being and health. Contributions of positive psychology. Annuary of Clinical and Health Psychology, 5, 15-27. 